\title{
1 Muscle spasms - a common symptom following theraphosid spider bites?
}

${ }^{1}$ Munich, 81377, Germany.

4

${ }^{2}$ GeneCology Research Centre, School of Science, Technology and Engineering, University of the Sunshine Coast, Sippy Downs, QLD 4556, Australia.

\# Correspondence: Tobias Hauke: t.hauke87@googlemail.com; Volker Herzig: vherzig@usc.edu.au, Tel.: +61-7-5456-5382.

\section{Highlights}

- We examined 363 published bites by theraphosid spiders on the incidence of skeletal muscle cramps in human bite victims

- Muscle cramps were caused by Theraphosidae from Africa, Asia, Australia, North and South America

- Highest incidence rates were recorded for theraphosid subfamilies Poecilotheriinae, Harpactirinae and Stromatopelminae

- Subfamilies with high incidence rates have a high likelihood of yielding larger venom amounts

\section{Abstract}

Despite the popularity of theraphosids, detailed reports on bite symptoms are still limited to few geographic regions and subfamilies. We therefore examined 363 published bite reports and noticed muscles cramps caused by theraphosids from nearly all continents and subfamilies. Symptoms are mostly locally restricted and mild, but $12.7 \%$ of victims experience pronounced cramps with highest incidence rates by Poecilotheriinae, Harpactirinae and Stromatopelminae subfamilies. We discuss how variations in venom quantity correlate with muscle cramp prevalence. 


\section{Keywords}

Theraphosidae; muscle cramps; convulsion; spider; envenomation; bite

\section{Graphical Abstract}

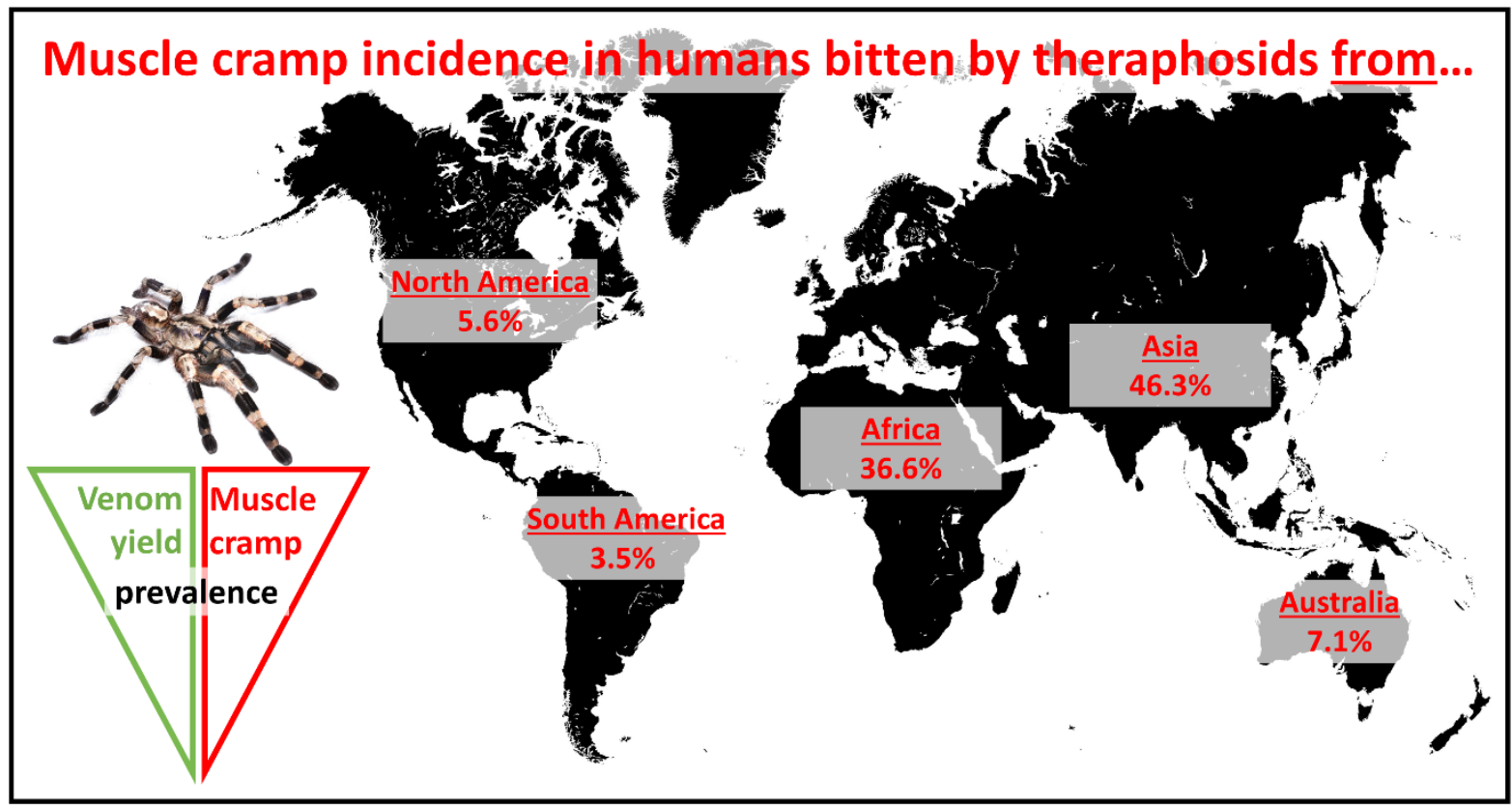

Spiders of the family Theraphosidae, commonly known as tarantulas or bird (-eating) spiders, are an important food source in some countries (Yen and Ro, 2013) and popular "exotic pets" in many countries throughout the world (Hauke and Herzig, 2020; Shivambu et al., 2020). However, as a result of the anthropogenic impact, several species are already regarded as endangered (Branco and Cardoso, 2020; Fukushima et al., 2020; Nanayakkara et al., 2015). Despite the popularity and importance of theraphosid spiders, the toxic effects of their bites on humans are rarely studied. Only two published studies gathered larger case series of bites by "wild" theraphosid spiders from Australia and Brazil, respectively, comprising a total of 57 incidents (Isbister et al., 2003; Lucas et al., 1994). The recorded bites exclusively resulted in minor outcomes, with local pain, puncture marks, redness, and swelling comprising the main effects (Isbister et al., 2003; Lucas et al., 1994). These local signs and symptoms don't necessarily imply an actual envenomation, but could at least be partly attributed to a mechanical irritation caused by the relatively large and powerful fangs of mygalomorph spiders (Isbister and Gray, 2004). With theraphosids gaining in popularity as pets, the 
likelihood of bite incidents in humans is increased. And as pet owners are usually well aware of the taxonomic identities of their maintained pets (Fuchs et al., 2014), such incidents typically fulfil the criteria of "verified bites" (Isbister and White, 2004). Thus, accidental bites from pet arachnids represent an opportunity to gain novel insights on the toxic effects of theraphosid venoms on humans.

Bite effects described from "pet" Poecilotheria regalis, Pterinochilus murinus and another unidentified Asian theraphosid spider highlighted the occurrence of muscle spasms in all three cases (Ahmed et al., 2009; Ahmed et al., 2010). In case of the bite caused by P. regalis the cramps were locally restricted to the bitten hand, while in the other two bites the cramps were considered to be generalized, affecting "virtually all [...] muscle groups", and experienced by the victims as agonizingly painful (Ahmed et al., 2009). Another study described one case of a bite from a "pet" $P$. regalis and gathered information on further 26 bites from Poecilotheria species (Fuchs et al., 2014). It was found that $58 \%$ of recorded Poecilotheria bites resulted in muscle cramps. The occurrence of muscle cramps was typically accompanied by several other local and systemic effects. Bite incidents, which resulted in muscle cramps amongst other effects, were experienced more unpleasant and painful than incidents that remained without muscle cramps. Most notably, it was found that muscle cramps caused by Poecilotheria have a delayed onset (on average starting 10 hours after the bite) and are longlasting (7.6 days on average) (Fuchs et al., 2014). A single case of a bite from a "pet" Heteroscodra maculata reported generalized muscle cramps, which started 4 hours and only receded about 2 weeks after bite (Fuchs et al., 2018). All of these previous reports were caused by pet spiders originating from Africa and Asia. Still, we expected that studying further reports would likely reveal the possibility of other theraphosids also causing muscle spasms. Only recently, we surveyed incidents caused by pet arachnids and, amongst others, gathered 285 bites from theraphosid spiders, which - to our knowledge - represents the largest study of bites by the spider family Theraphosidae published to date (Hauke and Herzig, 2020). The most common effects were local pain, swelling, puncture marks and redness, followed by muscle cramps.

In the present study, we aimed to analyse the incidence of skeletal muscle spasms in humans as a consequence of theraphosid spider bites and provide zoogeographic and phylogenetic implications (with Theraphosidae phylogeny according to Foley et al., 2019). To this end, we extracted data from published studies (de Haro and Jouglard, 1998; de Haro and Pommier, 
2003; Hauke and Herzig, 2020; Isbister et al., 2003; Lucas et al., 1994) and analysed several case reports (Ahmed et al., 2009; Dinamithra et al., 2013; Fuchs et al., 2018; Fuchs et al., 2014; Raven and Covacevich, 2012; Takaoka et al., 2001). In addition, we used data from 882 theraphosid venom extractions performed by one of the authors (V.H.) to correlate the venom yields with the respective spider sizes. In total, we compiled 363 bite incidents from theraphosid spiders (with 304 cases from "pet" and 59 from "wild" specimen) and muscle cramps occurred in $20.1 \%$ of all cases (Table 1 ). Notably, not all muscle cramps were experienced as agonizing as in the aforementioned literature (Ahmed et al., 2009), but some were described as rather mild (i.e. minor painful and/or locally restricted to bitten extremity). Cramps with an explicitly more pronounced manifestation (i.e. accompanied with agonizing pain and/or affecting several parts of the body) were recorded in $12.7 \%$ of all bites and comprised $63.0 \%$ of all cramps, respectively.

Table 1 shows that the incidence rates of muscle cramps caused by African (36.6\%) and Asian (46.3\%) theraphosids are considerably higher than those from Australian (7.1\%), North American (5.6\%) and South American species (3.5\%), but it also provides evidence that muscle cramps are not exclusive to Old World species (please note that there were no incidents from European species; accordingly, we refrain from drawing any conclusions on theraphosids from Europe). The proportion of pronounced muscle cramps is above $65 \%$ for African, Asian and North American theraphosids. Australian and South American species on the other hand exhibited much lower ratios $(0.0 \%$ and $20.0 \%$, respectively). Interestingly, $67.1 \%$ of all cramps were caused by representatives of the genera Poecilotheria and Pterinochilus, while the remaining 32.9\% were spread across 13 further genera (plus a further unidentified Asian genus (Ahmed et al., 2009; Ahmed et al., 2010)). Thus, these two Old Word genera appear to be the dominant cause for reported muscle cramps attributed to theraphosid spider bites.

Table 1: Overview on muscle cramps caused by theraphosid spiders from different geographical origins (data extracted from (Ahmed et al., 2009; de Haro and Jouglard, 1998; de Haro and Pommier, 2003; Dinamithra et al., 2013; Fuchs et al., 2018; Fuchs et al., 2014; Hauke and Herzig, 2020; Isbister et al., 2003; Lucas et al., 1994; Raven and Covacevich, 2012; Takaoka et al., 2001). ${ }^{a}$ Geographical origin (North America includes species from Central America) of theraphosids causing muscle cramps (and number of corresponding cases); ${ }^{b}$ Incidence rate of all reported muscle cramps (including mild and pronounced manifestations); Incidence rate of cramps with pronounced manifestation; ${ }^{d}$ Ratio of pronounced muscle cramps amongst all reported cramps; ${ }^{e}$ Theraphosid genera (and subfamilies) that caused muscle cramps; genera that caused pronounced muscle cramps are highlighted in bold. 


\begin{tabular}{|c|c|c|c|c|}
\hline Origin (cases) ${ }^{a}$ & All cramps ${ }^{b}$ & $\begin{array}{l}\text { Pronounced } \\
\text { cramps }^{c}\end{array}$ & Ratio $^{d}$ & Responsible theraphosid genera (subfamilies) ${ }^{e}$ \\
\hline Africa $(\mathrm{N}=71)$ & $36.6 \%$ & $23.9 \%$ & $65.4 \%$ & $\begin{array}{l}\text { Heteroscodra, Stromatopelma (each Stromatopelminae), } \\
\text { Hysterocrates, Pelinobius (each Eumenophorinae), Pterinochilus } \\
\text { (Harpactirinae) }\end{array}$ \\
\hline Asia ( $\mathbf{N}=\mathbf{8 2})$ & $46.3 \%$ & $31.7 \%$ & $68.4 \%$ & Haplopelma (Ornithoctoninae), Poecilotheria (Poecilotheriinae) \\
\hline Australia ( $N=14)$ & $7.1 \%$ & $0.0 \%$ & $0.0 \%$ & Selenocosmia (Selenocosmiinae) \\
\hline Europe $(\mathrm{N}=0)$ & \multicolumn{4}{|c|}{ No cases recorded } \\
\hline $\begin{array}{l}\text { North America } \\
(\mathrm{N}=54)\end{array}$ & $5.6 \%$ & $3.7 \%$ & $66.7 \%$ & Brachypelma, Phormictopus, Tliltocatl (each Theraphosinae) \\
\hline $\begin{array}{l}\text { South America } \\
(\mathrm{N}=142)\end{array}$ & $3.5 \%$ & $0.7 \%$ & $20.0 \%$ & $\begin{array}{l}\text { Avicularia (Aviculariinae), Grammostola, Pamphobeteus (each } \\
\text { Theraphosinae), Psalmopoeus (Psalmopoeinae) }\end{array}$ \\
\hline $\begin{array}{l}\text { Theraphosidae } \\
\text { Average ( } \mathrm{N}=363 \text { ) }\end{array}$ & $20.1 \%$ & $12.7 \%$ & $63.0 \%$ & \\
\hline
\end{tabular}

114

In agreement with previous publications (Ahmed et al., 2009; Andreev-Andrievskiy et al., 2017; Herzig and King, 2013), we think the muscle spasms are likely caused by toxins that target voltage-gated ion channels. However, as muscle spasms were recorded from several different, non-closely related Theraphosidae subfamilies (Figure $1 \mathrm{~A}$ ), any phylogenetic implications appear cryptic, and we cannot rule out that several different venom components (maybe even with additive or synergistic effects) rather than a single toxin are responsible for causing these symptoms. Besides toxicity, the available venom amount might be another important factor contributing to the prevalence of muscle cramps. We noticed that theraphosid subfamilies with high incidence rates for muscle cramps often have a high likelihood for yielding larger venom amounts upon "milking" (Figure 1B,C). Interestingly, members of the subfamily Poecilotherinae, which have the highest incidence rate for causing muscle cramps, also yield the highest venom amounts amongst all Theraphosidae subfamilies when comparing similarly sized spiders (Figure 1C). Accordingly, differences in the severity of symptoms and the prevalence of muscle cramps following theraphosid bites might be rather a consequence of varying venom amounts than of differences in venom toxicity. However, the "milked" venom quantities are only an estimate for the available venom amounts and the quantities that are actually administered during a bite might be influenced by various behavioural factors (Morgenstern and King, 2013). For example, spiders, in general, are known to use their venom sparingly, often even administering no venom (i.e. "dry bites") for defensive purposes (Nelsen et al., 2014). Furthermore, the ecological role for inflicting muscle spasms needs further elucidation. Humans are not amongst the natural prey of theraphosid 
136 spiders and a primary role as a defensive mechanism against larger predators appears unlikely 137 given the late onset of the cramps, often starting only several hours after the bite (Fuchs et 138 al., 2014). Interestingly, theraphosid venoms also cause similar symptoms including 139 convulsions in mice, but with a much quicker onset (Andreev-Andrievskiy et al., 2017; 140 Finlayson and Smithers, 1939) and it is known that theraphosids occasionally prey on small 141 vertebrates including mammals such as bats and rodents (Valdez, 2020). Accordingly, the 142 toxins responsible for causing muscle spasms may actually have evolved to target smaller 143 vertebrate prey, but a defensive purpose of these toxins against smaller vertebrate predators 144 can also not be ruled out. Nevertheless, much like the potential lethality of funnel-web spider 145 venom (Herzig et al., 2020), the agonizing effects of theraphosid venoms inducing muscle cramps in humans might have to be considered as an unfortunate evolutionary coincidence. 

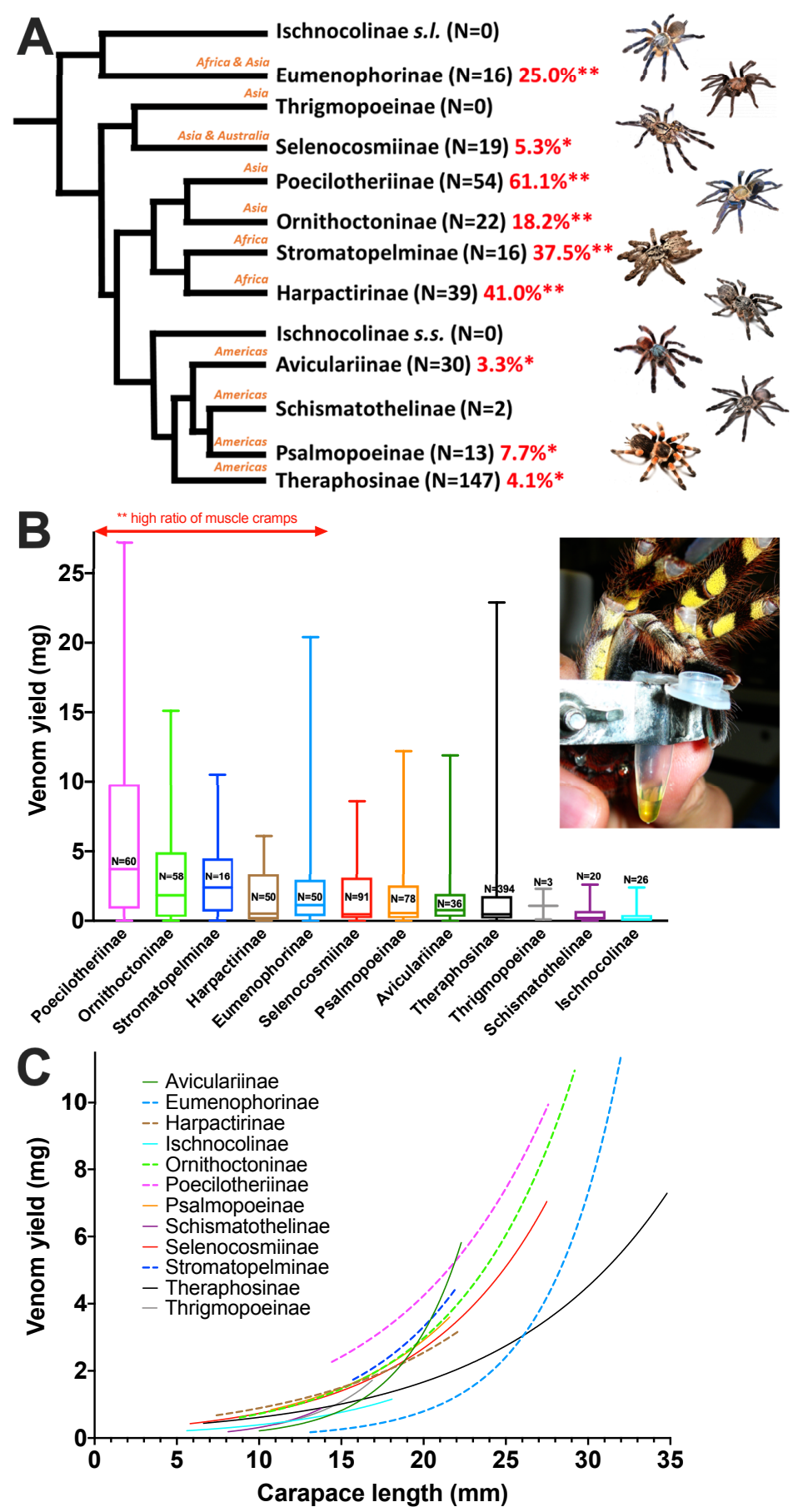

Figure 1: Muscle cramp incidence rates and venom yields in theraphosid subfamilies. A: Phylogeny (modified from (Foley et al., 2019)) of all theraphosid subfamilies (except Selenogyrinae; note that the subfamily Ischnocolinae appears paraphyletic, indicated by the two groups Ischnocolinae sensu stricto and Ischnocolinae sensu lato, and houses species from various continents). The continents of origin (in orange) and incidence rates of muscles cramps (in red) are indicated; ${ }^{*}=$ muscle cramps reported; ${ }^{* *}=$ high incidence rate $(>10 \%)$ of muscle cramps reported and respective case numbers $(\mathrm{N})$ according to Table 1. Photos of spiders were taken by one of the authors (T.H.) and represent theraphosid subfamilies, from which muscle cramps were reported (from top to bottom): Monocentropus balfouri (Eumenophorinae), Selenocosmia peerboomi (Selenocosminae), Poecilotheria ornata (Poecilotheriinae), Haplopelma lividum (Ornithoctoninae), Heteroscodra maculata 
157 (Stromatopelminae), Ceratogyrus darlingi (Harpactirinae), Caribena versicolor (Aviculariinae), Tapinauchenius 158 plumipes (Psalmopoeinae), and Brachypelma smithi (Theraphosinae). B: Box \& whisker plot of venom yields in different theraphosid subfamilies based on $\mathrm{N}=882$ electric "milkings" performed by one of the authors (V.H.) during which the carapace length was determined. The bottom and top line of each box indicate the 25 and 75 percentile, respectively, and the line inside the box denotes the median venom yield. The whiskers represent the minimum and maximum venom yield and the numbers of milkings are indicated separately for each subfamily. The red arrow marks those subfamilies with incidence rates for muscle cramps of above $10 \%$ according to panel A. Inset shows the milking (photo courtesy of Ingo Wendt) of a Poecilotheria fasciata by one of the authors (V.H.) yielding $19.2 \mathrm{mg}$ (when dried) of the yellow-colored venom, which is characteristic for this genus. C: Non-linear regression analysis with exponential growth (calculated in Prism 8 for macOS) for the venom yields in different theraphosid subfamilies based on the dataset of $\mathrm{N}=882$ milkings as detailed in panel $\mathrm{B}$. Subfamilies with a high incidence rate of muscle cramps according to panel A are indicated by dashed lines. The color scheme for the subfamilies corresponds to the respective colors in panel $\mathrm{B}$.

Previous attempts of relieving patients' muscle spasms and easing pain included the administration of benzodiazepines, magnesium and/or calcium, but remained without clear evidence for efficacy (Ahmed et al., 2009; Fuchs et al., 2018; Fuchs et al., 2014). Interestingly, in experiments in mice chlorpromazine, an antipsychotic drug, effectively suppressed muscle cramps (Andreev-Andrievskiy et al., 2017). However, at this stage chlorpromazine has not yet been evaluated on human bite victims for its potential to ameliorate muscle spasms. More research is therefore required to identify the theraphosid toxins responsible for causing skeletal muscle cramps and to elucidate their mode of action and their ecological role in the

\section{Conflict of interest}

The authors declare that there are no conflicts of interest.

\section{Acknowledgement}

The authors thank the members of the Deutsche Arachnologische Gesellschaft e.V. (DeArGe) for providing arachnids for milking, Annette Held and Witold Lapinski for providing theraphosids for photography. We also like to acknowledge Vectorworldmap.com for the world map that was included in the graphical abstract. V.H. is funded by an Australian 
References

191

192

193

194

195

196

197

198

199

200

201

202

203

204

205

206

207

208

209

210

211

212

213

214

215

216

217

218

219

220

221

222

223

224

225

226

227

228

229

230

231

232

Ahmed, N., Pinkham, M., Warrell, D.A., 2009. Symptom in search of a toxin: Muscle spasms following bites by Old World tarantula spiders (Lampropelma nigerrimum, Pterinochilus murinus, Poecilotheria regalis) with review. Qjm-Int. J. Med. 102, 851-857.

Ahmed, N., Pinkham, M., Warrell, D.A., Verdez, J.M., 2010. Corrigendum: Symptom in search of a toxin: Muscle spasms following bites by Old World tarantula spiders (Lampropelma nigerrimum, Pterinochilus murinus, Poecilotheria regalis) with review (vol 102, pg 851, 2009). Qjm-Int. J. Med. 103, 203-204.

Andreev-Andrievskiy, A., Popova, A., Lagereva, E., Osipov, D., Berkut, A., Grishin, E., Vassilevski, A., 2017. Pharmacological analysis of Poecilotheria spider venoms in mice provides clues for human treatment. Toxicon 138, 59-67.

Branco, V.V., Cardoso, P., 2020. An expert-based assessment of global threats and conservation measures for spiders. Glob. Ecol. Conserv. 24.

de Haro, L., Jouglard, J., 1998. The dangers of pet tarantulas: Experience of the Marseilles Poison Centre. J. Toxicol. Clin. Toxicol. 45, 214-216.

de Haro, L., Pommier, P., 2003. Envenomation: A real risk of keeping exotic house pets. Vet. Hum. Toxicol. 45, 214-216.

Dinamithra, N.P., Sivansuthan, S., Johnson, P., Nishshanka, J.G.P., 2013. Clinical presentation and outcome of Sri-Lankan ornamental tarantula Poecilotheria fasciata spider bite: a case report. Anuradhapura Med. J. 7, 10-12.

Finlayson, M.H., Smithers, R., 1939. Harpactirella lightfooti as a cause of spider-bite in the Union. S. Afr. Med. J. 13, 808-810.

Foley, S., Lueddecke, T., Cheng, D.Q., Krehenwinkel, H., Kunzel, S., Longhorn, S.J., Wendt, I., von Wirth, V., Taenzler, R., Vences, M., Piel, W.H., 2019. Tarantula phylogenomics: A robust phylogeny of deep theraphosid clades inferred from transcriptome data sheds light on the prickly issue of urticating setae evolution. Mol. Phylogenet. Evol. 140, 106573.

Fuchs, J., Martin, N.C., Rauber-Luthy, C., 2018. A verified bite by Heteroscodra maculata (Togo starburst or ornamental baboon tarantula) resulting in long-lasting muscle cramps. Clin. Toxicol. $56,675-676$.

Fuchs, J., von Dechend, M., Mordasini, R., Ceschi, A., Nentwig, W., 2014. A verified spider bite and a review of the literature confirm Indian ornamental tree spiders (Poecilotheria species) as underestimated theraphosids of medical importance. Toxicon 77, 73-77.

Fukushima, C.S., Cardoso, P., Bertani, R., 2020. Description of the male of the critically endangered tarantula Typhochlaena curumim Bertani, 2012 (Araneae, Theraphosidae), with comments on tarantula trade and conservation. Zookeys 938, 125-136.

Hauke, T.J., Herzig, V., 2020. Love bites - Do venomous arachnids make safe pets? Toxicon, accepted 6.12.2020.

Herzig, V., King, G.F., 2013. The neurotoxic mode of action of venoms from the spider family Theraphosidae, in: Nentwig, W. (Ed.), Spider Ecophysiology Springer, Heidelberg, pp. 203-215.

Herzig, V., Sunagar, K., Wilson, D.T.R., Pineda, S.S., Israel, M.R., Dutertre, S., McFarland, B.S., Undheim, E.A.B., Hodgson, W.C., Alewood, P.F., Lewis, R.J., Bosmans, F., Vetter, I., King, G.F., Fry, B.G., 2020. Australian funnel-web spiders evolved human-lethal delta-hexatoxins for defense against vertebrate predators. Proc. Natl. Acad. Sci. USA 117, 24920-24928.

Isbister, G.K., Gray, M.R., 2004. Bites by Australian mygalomorph spiders (Araneae, Mygalomorphae), including funnel-web spiders (Atracinae) and mouse spiders (Actinopodidae: Missulena spp).

Toxicon 43, 133-140.

Isbister, G.K., Seymour, J.E., Gray, M.R., Raven, R.J., 2003. Bites by spiders of the family Theraphosidae in humans and canines. Toxicon 41, 519-524. 
Isbister, G.K., White, J., 2004. Clinical consequences of spider bites: recent advances in our understanding. Toxicon 43, 477-492.

Lucas, S.M., Da Silva, P.I., Jr., Bertani, R., Cardoso, J.L.C., 1994. Mygalomorph spider bites: A report on 91 cases in the state of Sao Paulo, Brazil. Toxicon 32, 1211-1215.

Morgenstern, D., King, G.F., 2013. The venom optimization hypothesis revisited. Toxicon 63, 120-128. Nanayakkara, R.P., Ganehiarachchi, G.A.S.M., Vishvanath, N., Kusuminda, T.G.T., 2015. Discovery of the critically endangered tarantula species of the genus Poecilotheria (Araneae: Theraphosidae), Poecilotheria hanumavilasumica, from Sri Lanka. J. Asia Pac. Biodivers. 8, 1-6.

Nelsen, D.R., Kelln, W., Hayes, W.K., 2014. Poke but don't pinch: risk assessment and venom metering in the western black widow spider, Latrodectus hesperus. Anim. Behav. 89, 107-114.

Raven, R.J., Covacevich, J.A., 2012. New information on envenomation by a whistling spider, Phlogius crassipes (family Theraphosidae). Queensland Nat. 50, 19-22.

Shivambu, T.C., Shivambu, N., Lyle, R., Jacobs, A., Kumschick, S., Foord, S.H., Robertson, M.P., 2020. Tarantulas (Araneae: Theraphosidae) in the pet trade in South Africa. Afr. Zool. 55, 323-336.

Takaoka, M., Nakajima, S., Sakae, H., Nakamura, T., Tohma, Y., Shiono, S., Tabuse, H., 2001. Tarantulas bite: Two case reports of finger bite from Haplopelma lividum. Chudoku Kenkyu 14, 247-250.

Valdez, J.W., 2020. Arthropods as vertebrate predators: A review of global patterns. Glob. Ecol. Biogeogr. 29, 1691-1703.

Yen, A.L., Ro, S., 2013. The sale of tarantulas in Cambodia for food or medicine: Is it sustainable? J. Threat. Taxa 5, 3548-3551. 